\title{
PENGARUH GAYA KEPEMIMPINAN KAPOLSEK TERHADAP KINERJA ANGGOTANYA DI POLSEK WONOBOYO KABUPATEN TEMANGGUNG
}

\author{
Vuvud Marinda W' ${ }^{1}$, Rita Rachmawati ${ }^{2}$, Euis Salbiah ${ }^{3}$ \\ ${ }^{1}$ Jurusan Ilmu Administrasi Negara Fakultas Ilmu Sosial dan Ilmu Politik Universitas \\ Djuanda, Jl. Tol Ciawi No. 1 Kotak Pos 35 Bogor 16770 \\ ${ }^{2}$ Jurusan Ilmu Administrasi Negara Fakultas Ilmu Sosial dan Ilmu Politik Universitas \\ Djuanda, Jl. Tol Ciawi No. 1 Kotak Pos 35 Bogor 16770 \\ ${ }^{3}$ Jurusan Ilmu Administrasi Negara Fakultas Ilmu Sosial dan Ilmu Politik Universitas \\ Djuanda, Jl. Tol Ciawi No. 1 Kotak Pos 35 Bogor 16770
}

(Diterima oleh Dewan Redaksi: 01-08-2016)

(Dipublikasikan oleh Dewan Redaksi: 01-10-2016)

\begin{abstract}
Police sector (police) Wonoboyo an element of the duties and authority of the law of the District Police region Wonoboyo Temanggung regency, Central Java province which is an extension of the internal security duty Police Resort (Police). Noted region Wonoboyo police law in 2016 to the month of February there were 5 cases consisting of 4 times the theft as well as the first time fraud. Thus, only $36.97 \%$ of cases that can be resolved by the Police Criminal Investigation Unit Wonoboyo, or in other words the police officer performance Wonoboyo still low. The method used in this research is quantitative approach to research is descriptive, the research focused on solving the problem was investigated by using file state the subject or object of research is happening now based on factors that seen in the field as it should be or is used to describe a fact or systematic character defined population, actual and precise. The results of this study indicate that the leadership style adopted by the Chief of Police Sector Wonoboyo obtained 3.68 figure with a good assessment criteria. While the performance results obtained with the 4.50 figure Excellent assessment criteria. It is clear that the leadership style adopted by the Chief of Police Sector Wonoboyo obtained 3.68 figure with a good assessment criteria. This is influenced by leadership style (10.4\%) and (89.6\%) by other factors, such as motivation, supervision, etc., but not studied. The conclusion of this research in general is a style of leadership, the Chief of Police Sector Wonoboyo considerable influence despite the need for improvement especially in terms of giving confidence to subordinates to make decisions and give freedom to members to cooperate with other units.
\end{abstract}

Keywords: leadership style, performance, Police.

\begin{abstract}
ABSTRAK
Keploisian sektor (Polsek) Wonoboyo merupakan unsur pelaksanaan tugas dan wewenang Polri diwilayah hukum Kecamatan Wonoboyo Kabupaten Temanggung Provinsi Jawa Tengah yang merupakan perpanjangan tugas Kamtibmas dari Polisi Resort (Polres). Tercatat diwilayah hukum Polsek Wonoboyo pada tahun 2016 hingga bulan februari ada 5 kasus terdiri dari 4 kali tindak pencurian serta 1 kali penipuan. Dengan demikian, hanya 36,97\% kasus yang bisa diselesaikan oleh Satuan Reserse Kriminal Polsek Wonoboyo, atau dengan kata lain kinerja pegawai Polsek Wonoboyo masih rendah. Metode yang digunakan dalam penelitian ini adalah pendekatan kuantitatif dengan penelitian bersifat deskriptif, yakni penelitian yang memusatkan perhatian kepada pemecahan masalah yang diselidiki
\end{abstract}


dengan menggunakan berkas keadaan subjek atau objek penelitian yang terjadi sekarang berdasarkan faktor-faktor yang dilihat dilapangan sebagaimana mestinya atau digunakan untuk melukiskan fakta atau karakter populasi tertentu secara sistematis, aktual dan tepat. Hasil penelitian ini menunjukkan bahwa gaya kepemimpinan yang diterapkan oleh Kepala Polisi Sektor Wonoboyo di peroleh angka 3,68 dengan kriteria penilaian baik. Sedangkan hasil kinerja di peroleh angka 4,50 dengan kriteria penilaian Sangat baik. Hal ini menjelaskan bahwa gaya kepemimpinan yang diterapkan oleh Kepala Polisi Sektor Wonoboyo di peroleh angka 3,68 dengan kriteria penilaian baik. Hal ini dipengaruhi oleh Gaya kepemimpinan $(10,4 \%)$, dan $(89,6 \%)$ oleh faktor lain, seperti motivasi, pengawasan, dan lain-lain, tapi tidak diteliti. Kesimpulan dari penelitian ini secara umum adalah Gaya kepemimpinan Kepala Polisi Sektor Wonoboyo cukup berpengaruh meskipun perlu adanya peningkatan terutama dalam hal memberikan kepercayaan kepada bawahan untuk mengambil keputusan serta memberikan kebebasan kepada anggota untuk bekerjasama dengan unit lain.

Kata Kunci : Gaya kepemimpinan, Kinerja, Kapolsek.

Vuvud Marinda W, 2016, Pengaruh Gaya Kepemimpinan Kapolsek Terhadap Kinerja Anggotanya Di Polsek Wonoboyo Kabupaten Temanggung.. Jurnal Governansi. 


\section{PENDAHULUAN}

Kepolisian Negara Republik Indonesia (Polri) merupakan suatu organisasi bidang pelayanan publik serta alat Negara yang memberikan perlindungan, pengayoman, dan pelayanan masyarakat. Berdasarkan undang-undang No 2 Tahun 2002 tentang Kepolisian Negara Republik Indonesia dan dalam Bab II Tap MPR No. VII/2000 menyebutkan bahwa (1) Polri merupakan alat negara yang berperan dalam memelihara Kamtibmas, menegakkan hukum, memberikan pengayoman dan pelayanan kepada masyarakat. (2) Dalam menajalankan perannya, Polri wajib memiliki keahlian dan ketrampilan secara profesional. Artinya Polri bukan suatu lembaga/badan non departemen tapi dibawah Presiden sebagai Kepala Negara bukan Kepala Pemerintahan.

Dalam melaksanakan fungsi dan peranya diseluruh wilayah negara republik Indonesia tersebut dapat berjalan dengan efektif dan efisien, maka wilayah negara Republik Indonesia dibagi dalam daerah hukum menurut kepentingan pelaksanaan tugas Kepolisian Negara Republik Indonesia, sebagaimana yang ditentukan dalam peraturan pemerintah wilayah kepolisian dibagi secara berjenjang mulai tingkat pusat yang biasa disebut Markas Besar Polri yang wilayah kerjanya meliputi seluruh wilayah negara Republik Indonesia yang dipimpin oleh seorang Kapolri yang bertanggung jawab kepada Presiden.

Kemudian wilayah ditingkat provinsi disebut dengan Kepolisian Daerah yang lazim disebut dengan Polda yang dipimpin oleh seorang Kapolda yang bertanggung jawab kepada Kapolri, di tingkat Kabupaten disebut dengan Kepolisian Resort atau disebutjuga Polres yang dipimpin oleh seorang Kapolres yang bertanggung jawab kepada Kapolda, dan ditingkat Kecamatan ada Kepolisian Sektor yang biasa disebut dengan Polsek dengan pimpinan seorang Kapolsek yang bertanggung jawab kepada Kapolres.

Tercatat diwilayah hukum Polsek Wonoboyo pada tahun 2014 terdaftar kasus yang dilaporkan 17 kasus (3 kasus KDRT, 5 kasus pencurian, 3 kasus penipuan, 2 kasus perzinaan, 2 kasus pengrusakan, 2 kasus penganiayaan) dan kasus yang selesai hanya sebanyak 8 kasus. Pada tahun 2015 terdaftar 26 kasus (15 kasus pencurian, 2 kasus penganiayaan, 4 kasus penipuan, 4 kasus penggelapan, dan 1 kasus pengrusakan) jumlah yang dilaporkan yang tertangani yang berlanjut sampai pengadilan 4 kasus dan kasus yang selesai hanya 7 kasus. Pada tahun 2016 hingga bulan februari ada 5 kasus terdiri dari 4 kali tindak pencurian serta 1 kali penipuan. Dengan demikian, hanya 36,97\% kasus yang bisa diselesaikan oleh Satuan Reserse Kriminal Polsek Wonoboyo, atau dengan kata lain kinerja pegawai Polsek Wonoboyo masih rendah.

Oleh karenanya, maka sesuai doktrinnya bahwa polisi harus melaksanakan tugas dan kewajiban secara profesional dengan mengedepankan integritas yang tinggi. Sehingga peran kepemimpinan Kapolsek diperlukan agar Kepemimpinan Kapolsek diperlukan agar para anggotanya dapat memerankan fungsinya dan menghasilkan kinerja yang baik.

Berdasarkan latar belakang yang dikemukakan di atas, maka penulis tertarik 
1. untuk melakukan penelitian dengan judul "Pengaruh Gaya Kepemimpinan Kapolsek Terhadap Kinerja Anggotanya di Polsek Wonoboyo Kabupaten Temanggung".

\section{MATERI DAN METODE}

Metode penelitian adalah cara yang ditempuh untuk mendapat data yang akurat dan representatif. Mencakup penggunaan bebrapa teknik, seperti teknik pengambilan contoh teknik pengukuran, teknik pengumpulan data. Menurut Sugiyono (2012:14), metode penelitian kuantitatif diartikan sebagai metode penelitian yang berlandaskan pada filsafat positivism, digunakan untuk meneliti dilakukan secara random, pengumpulan data menggunakan instrumen penelitian, analisis dan bersifat kuantitatif/statistik dengan tujuan untuk menguji hipotesis yang telah ditetapkan.

Penelitian ini mengkaji mengenai

“Pengaruh Gaya Kepemimpinan Kepala

Kepolisian Sektor (Kapolsek) Terhadap Kinerja Anggotanya di Polsek Wonoboyo

Kabupaten Temanggung".Melalui penelitian ini akan dapat diketahui mengenai pengaruh gaya kepemimpinan terhadp kinerja, apakah gaya kepemimpinan Kapolsek membuat kinerja angggotanya menjadi lebih baik atau tidak. Oleh karena itu, untuk mencapai tujuan tersebut, penelitian ini menggunakan pendekatan kualitatif dengan penelitian bersifat deskriptif, yakni penelitian yang memusatkan perhatian kepada masalahmasalah aktual.
Populasi yang digunakan dalam penelitian ini adalah anggota Kepolisian Sektor Wonoboyo Kabupaten Temanggung. Menurut Sugiyono, sampel adalah bagian dari jumlah dan karakteristik yang dimiliki oleh populasi tersebut. Bila populasi besar, dan peneliti tidak mungkin mempelajari semua yang ada pada populasi misalnya karena keterbatasan dana, tenaga dan waktu, maka penelitian dapat menggunakan sampel yang diambil dari populasi itu. Apa yang dipelajari dari sampel itu kesimpulannya akan dapat diberlakukan untuk populasi. Untuk itu sampel yang diambil dari populasi harus betul-betul representative (mewakili).

Pada bagian lainnya, Sugiyono mengemukakan bahwa salah satu sampel yang termasuk teknik nonprobability sampling itu adalah sampling jenuh (semua populasi dijadikan sampel karena berjumlah kurang dari 30 orang) dan dipandang cocok untuk penelitian ini. Sampel dalam penelitian ini adalah seluruh anggota Kepolisian Sektor Wonoboyo Kabupaten Temanggung.

Dalam penelitian ini peneliti menggunakan teknik interview/ wawancara terstruktur dan kuesioner, dan dalam penelitian Kuantitatif analisis data merupakan kegiatan setelah data dari seluruh responden atau sumber data lain terkumpul. Kegiatan dalam analisa data adalah mengelompokan data berdasarkan variabel dan jenis responden, mentabulasi data berdsarkan variabel dari seluruh responden, menyajikan data tiap variable yang teliti, melakukan perhitungan untuk menjawab rumusan masalah. Metode Penelitian Kepustakaan (Library research) Dengan cara ini data diperoleh dari sumber- sumber tertentu, yaitu:

1) Buku-buku yang berhubungan dengan penelitian yang dilakukan. 
2) Tulisan-tulisan ilmiah. Artikelartikel dan lain-lain.

3) Bahan-bahan yang terdri dari undang-undang dan peraturanperaturan lain yang relevan dengan judul skripsi. (bahan primer)

Untuk mempermudah analisis data dan penarikan kesimpulan makan disamping menggunakan perhitungan presentase juga dilakukan dengan menggunakan statistic deskriptif yaitu dengan menggunakan tabel frekuensi dan menggunakan perhitungan rata-rata. Cara ini biasanya dengan menggunakan perhitungan Weight Mean Score (WMS) yaitu dilakukan pembobotan untuk setiap jawaban pilihan. Dengan memberikan skor tersebut, maka akan diperoleh variasi jawaban yang bergerak 1-5, karena itu interval antara satu criteria dengan kriteria lainnya yang diperoleh angka sebesar 0,8 .

Angka ini diperoleh setelah ada nya pengurangan dari nilai tertinggi lalu dikurangi nilai terendah dan dibagi banyaknya alternative jawaban. Sehingga diperoleh hasil sebagai berikut:

$$
\begin{aligned}
& I=\frac{S K T-S K R}{V} \\
& I=\frac{5-1}{5}=0,8
\end{aligned}
$$

Keterangan:

I = Interval

SKT = Skor tertinggi

SKR $=$ Skor terendah

$\mathrm{V}=$ Jumlah

Dari ketentuan diatas maka tingkat kategori jawaban yang diperoleh itentukan

dengan kriteria penafsiran sebagai berikut:
Tabel 1.1

Kriteria Penafsiran

\begin{tabular}{|c|c|}
\hline Skor & Kriteria \\
\hline $4,21-5,00$ & Sangat baik \\
\hline $3,41-4,20$ & Baik \\
\hline $2,61-3,40$ & Sedang \\
\hline $1,81-2,60$ & Buruk \\
\hline $1,00-1,80$ & Sangat buruk \\
\hline
\end{tabular}

Data yang diperoleh diolah berdasarkan jawaban responden melalui angket yang menggunakan rumus WMS:

$$
M=\frac{E(f x)}{n}
$$

Keterangan:

$M=$ Perolehan angka enafsiran

$\mathrm{f}=$ Frekuensi jawaban

$\mathrm{x}=$ Pembobotan (skala ilai)

$\mathrm{E}=$ Penjumlahan

$\mathrm{n}=$ Jumlah seluruh jawaban responden Kemudian setelah langkah pertama

selesai dilakukan, maka selanjutnya dibuat tabel sebagai berikut:

Tabel 1.2

\section{Contoh Tabel Analisis}

\begin{tabular}{|c|l|c|c|c|c|}
\hline No & $\begin{array}{l}\text { Alternatif } \\
\text { Jawaban }\end{array}$ & $\mathbf{F}$ & $\mathbf{( x )}$ & $\begin{array}{l}\mathbf{F}(\mathbf{x} \\
\mathbf{J}\end{array}$ & $\mathbf{M}=\frac{\mathbf{E} \mathbf{f}(\mathbf{x})}{\mathbf{N}}$ \\
\hline 1 & Selalu & & 5 & & \\
\hline 2 & Sering & & 4 & & \\
\hline 3 & $\begin{array}{l}\text { Kadang - } \\
\text { Kadang }\end{array}$ & & & \\
\hline 4 & $\begin{array}{l}\text { Hampir } \\
\text { Tidak }\end{array}$ & & 2 & & \\
\hline & Pernah & & & \\
\hline 5 & Tidak Pernah & 1 & & \\
\hline & Jumlah & & & \\
\hline
\end{tabular}


Uji signifikasi yang lain juga dapat menggunakan aplikasi SPSS 16.00. Setelah melewati tahap perhitungan, maka untuk mengetahui tingkat hubungan antara variabel x (Gaya kepemimpinan Kapolsek) dengan variabel y (Kinerja Anggotanya) digunakan pedoman interpretasi korelasi menurut pendapat sugiyono.

\section{Tabel 1.3}

\section{Pedoman untuk memberikan}

\section{Interpretasi Koefisen Korelasi}

\begin{tabular}{|c|c|}
\hline Interval & Tingakat \\
\hline Koefisien & hubungan \\
\hline $0,20-0,399$ & Rendah \\
\hline $0,40-0,599$ & Sedang \\
\hline $0,60-0,799$ & Kuat \\
\hline $0,80-1,000$ & Sangat Kuat \\
\hline
\end{tabular}

Sumber : Sugiyono 2012 : 214

Selanjutnya untuk mengetahui sejauhmana variabel (x) memberikan kontribusinya terhadap variabel (y) dalam penelitian ini, maka digunakan perhitungan koefisien determinasi (Kd), yaitu:

$\mathrm{Kd}=\mathrm{p} 2 \times 100 \%$

Keterangan: $\mathrm{Kd}=$ Koefisien determinasi $\mathrm{P}=$ Koefisen Korelasi

\section{HASIL DAN PEMBAHASAN}

4.1. Gambaran Lokus Penelitian

\subsubsection{Kondisi Geografis}

Kabupaten Temanggung terletak di tengah-tengah Propinsi Jawa Tengah dengan bentangan utara ke selatan 46,8 $\mathrm{km}$ dan timur ke barat $43 \mathrm{~km}$. Kabupaten Temanggung secara geografis terletak diantara $110023-11004630$ bujur timur dan $7014-703^{2} 35$ selatan dengan luas wilayah 870,65 km2 (87.065 Ha).

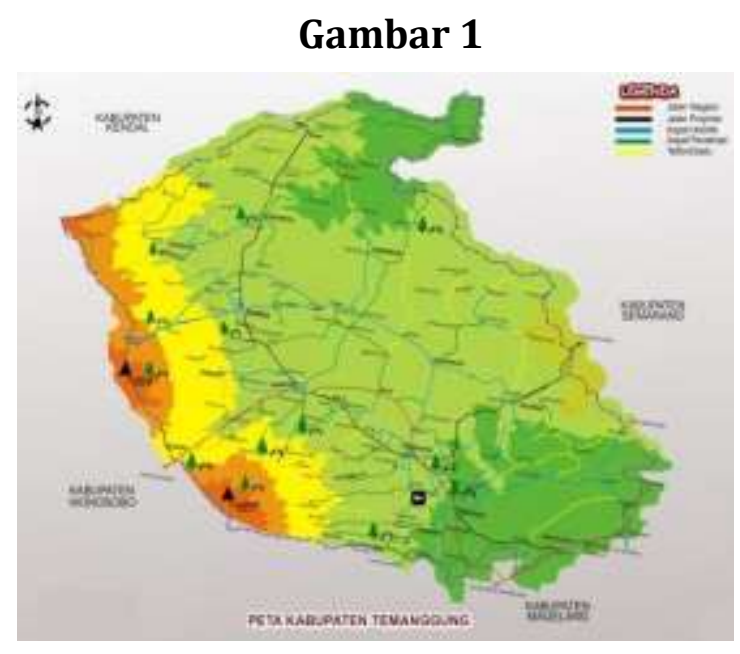

Tabel 1.4

\section{Jumlah Desa dan penduduk} Kecamatan Wonoboyo

\begin{tabular}{|c|c|c|}
\hline No & Nama Desa & $\begin{array}{c}\text { Jumlah } \\
\text { Penduduk }\end{array}$ \\
\hline 1. & Desa Wonoboyo & 7.232 jiwa \\
\hline 2. & Desa Pateken & 4.320 jiwa \\
\hline 3. & Desa Pitrosari & 2.123 jiwa \\
\hline 4. & Desa Purwosari & 6.221 jiwa \\
\hline 5. & Desa Kebonsari & 4.381 jiwa \\
\hline 6. & Desa Semen & 2.123 jiwa \\
\hline 7. & Desa Tening & 1.252 jiwa \\
\hline 8. & Desa Wonocoyo & 6.320 jiwa \\
\hline 9. & Desa Pesantren & 3.052 jiwa \\
\hline 10. & Desa Rejosari & 4.221 jiwa \\
\hline 11. & Desa Tawangsari & 1.023 jiwa \\
\hline 12. & Desa Cemoro & 1.167 jiwa \\
\hline 13. & Desa Wates & 2.305 jiwa \\
\hline & Jumlah & 45.740 wa \\
\hline
\end{tabular}

\subsection{Profil Informan/ Identitas Responden}

Polsek

Wonoboyo yang merupakan lembaga merupakan salah satu unsur yang menjadi objek penelitian 
dengan subjek anggota kepolisian yang berjumlah 16 orang yaitu sebagai berikut

Tabel 1.5

Jumlah anggota Polsek Wonoboyo

\begin{tabular}{|c|c|c|c|c|}
\hline No & Nama & NRP & Pangkat & Jabatan \\
\hline 1. & $\begin{array}{l}\text { Suwondo, } \\
\text { S.H }\end{array}$ & $\begin{array}{c}7208047 \\
7\end{array}$ & AK P & Kapolsek \\
\hline 2. & $\begin{array}{l}\text { Hasanbisr } \\
\mathrm{i}\end{array}$ & $\begin{array}{c}6512031 \\
0\end{array}$ & IPDA & Waka Polsek \\
\hline 3. & $\begin{array}{l}\text { Agung } \\
\text { Y,S.H }\end{array}$ & $\begin{array}{c}7209015 \\
8\end{array}$ & AIPTU & $\begin{array}{c}\text { Kanit } \\
\text { Reskrim }\end{array}$ \\
\hline 4. & Febru H & $\begin{array}{c}6702010 \\
8\end{array}$ & AIPTU & $\begin{array}{c}\text { Kanit } \\
\text { Sabhara }\end{array}$ \\
\hline 5. & Suparjo & $\begin{array}{c}5906060 \\
7\end{array}$ & BRIPKA & Ka SPK \\
\hline 6. & $\begin{array}{l}\text { Sumardio } \\
\text { no }\end{array}$ & $\begin{array}{c}6009032 \\
3\end{array}$ & AIPTU & Kanit Provos \\
\hline 7. & Ahmat & \begin{tabular}{|r|}
610801 \\
45 \\
\end{tabular} & AIPTU & Kasi Humas \\
\hline 8. & Subadi & $\begin{array}{r}631000 \\
39 \\
\end{array}$ & AIPTU & $\begin{array}{c}\text { Kanit } \\
\text { Binmas } \\
\end{array}$ \\
\hline 9. & Andika N & $\begin{array}{r}860306 \\
39 \\
\end{array}$ & BRIPKA & Kanit Intel \\
\hline 10. & $\begin{array}{l}\text { M } \\
\text { Aschabu }\end{array}$ & $\begin{array}{r}871202 \\
92 \\
\end{array}$ & BRIPOL & Kasi Umum \\
\hline 11. & Gunarto & $\begin{array}{r}840220 \\
01 \\
\end{array}$ & BRIPKA & Binmas \\
\hline 12. & Tri Jaya. P & $\begin{array}{r}831004 \\
94 \\
\end{array}$ & BRIPOL & Binmas \\
\hline 13. & Joko. S & $\begin{array}{r}850209 \\
82 \\
\end{array}$ & BRIPOL & Binmas \\
\hline 14. & Andika.W & $\begin{array}{r}830603 \\
26 \\
\end{array}$ & BRIPOL & Binmas \\
\hline 15. & Wahyu.A & \begin{tabular}{|r|}
850519 \\
33 \\
\end{tabular} & BRIPOL & Binmas \\
\hline 16. & Taufil & $\begin{array}{r}870508 \\
18 \\
\end{array}$ & BRIPOL & Binmas \\
\hline 17. & $\begin{array}{l}\text { A.Dwisant } \\
\text { o }\end{array}$ & $\begin{array}{r}870611 \\
98 \\
\end{array}$ & BRIPOL & Binmas \\
\hline
\end{tabular}

Sumber : Profil Polsek Wonoboyo 2016

\subsection{Hasil dan Analisa Data}

\section{A. Analisis deskriptif data variable (x) Gaya Kepemimpinan}

Dari hasil penelitian Penulis akan menguraikan jawaban responden terhdap beberapa indikator pertanyaan mengenai Dimensi Teknik Gaya Kepemimpinan sebagai berikut :

Tabel 1.6

Rekapitulasi Jawaban Responden Tentang Gaya Kepemimpinan di Polsek Wonoboyo Kabupaten Temanggung

\begin{tabular}{|c|l|c|c|}
\hline $\mathbf{N o}$ & Indikator & Skor & $\begin{array}{c}\text { Penafsira } \\
\text { n }\end{array}$ \\
\hline $\mathbf{1}$ & $\begin{array}{l}\text { Memberi kesempatan kepada } \\
\text { bawahannya untuk } \\
\text { mengetahui apa yang } \\
\text { diharapkan dilakukannya }\end{array}$ & 3,93 & Baik \\
\hline $\mathbf{2}$ & Menjadwalkan pekerjaan & 3.56 & Baik \\
\hline $\mathbf{3}$ & $\begin{array}{l}\text { Memberikan pedoman yang } \\
\text { spesifik mengenai cara } \\
\text { menyelesaikan tugas }\end{array}$ & 3.37 & Sedang \\
\hline $\mathbf{4}$ & $\begin{array}{l}\text { Memberikan pedoman yang } \\
\text { spesifik mengenai cara } \\
\text { menyelesaikan tugas }\end{array}$ & 3,62 & Baik \\
\hline $\mathbf{5}$ & $\begin{array}{l}\text { Menunjukkan sikap ramah } \\
\text { kepada bawahan }\end{array}$ & 3,87 & Baik \\
\hline $\mathbf{6}$ & $\begin{array}{l}\text { Memberikan perhatian } \\
\text { terhadap kebutuhan bawahan }\end{array}$ & 4,00 & Baik \\
\hline $\mathbf{7}$ & $\begin{array}{l}\text { Mendukung yang dilakukan } \\
\text { bawahan dalam penyelesaian } \\
\text { pekerjaan }\end{array}$ & 3,50 & Baik \\
\hline $\mathbf{8}$ & $\begin{array}{l}\text { Memberi kesempatan untuk } \\
\text { peningkatkan prestasi dan } \\
\text { karir }\end{array}$ & 3,81 & Baik \\
\hline $\mathbf{9}$ & $\begin{array}{l}\text { Berkonsultasi kepada } \\
\text { bawahan }\end{array}$ & 3,00 & Sedang \\
\hline $\mathbf{1 0}$ & $\begin{array}{l}\text { Menggunakan saran bawahan } \\
\text { sebelum mengambil keputusan }\end{array}$ & 3,12 & Sedang \\
\hline & $\begin{array}{l}\text { Memberikan kesempatan } \\
\text { untuk mengemukakan saran } \\
\text { dan gagasan }\end{array}$ & 4,25 & Sangat Baik \\
\hline $\mathbf{1 2}$ & $\begin{array}{l}\text { Terbuka terhadap kritik dan } \\
\text { saran dari bawahan }\end{array}$ & 3,43 & Baik \\
\hline
\end{tabular}




\begin{tabular}{|c|l|c|c|}
\hline $\mathbf{1 3}$ & $\begin{array}{l}\text { Menetapkan sasaran yang } \\
\text { menantang }\end{array}$ & 3,50 & Baik \\
\hline $\mathbf{1 4}$ & $\begin{array}{l}\text { Mengharapkan bawahan } \\
\text { untuk berprestasi pada } \\
\text { tingkat tertinggi }\end{array}$ & 4,18 & Baik \\
\hline $\mathbf{1 5}$ & $\begin{array}{l}\text { Memberikan imbalan atau } \\
\text { hadiah kepada bawahan } \\
\text { yang berprestasi }\end{array}$ & 3,00 & Sedang \\
\hline $\mathbf{1 6}$ & $\begin{array}{l}\text { Mengharapkan kualitas } \\
\text { dan ketelitian kepada } \\
\text { bawahan saat bertugas }\end{array}$ & 3,93 & Baik \\
\hline $\mathbf{1 7}$ & $\begin{array}{l}\text { Memberikan kesempatan } \\
\text { kepada bawahan untuk } \\
\text { mengoptimalkan } \\
\text { kemampuannya }\end{array}$ & 3,43 & Baik \\
\hline $\mathbf{1 8}$ & $\begin{array}{l}\text { Memberikan kepercayaan } \\
\text { kepada bawahan untuk } \\
\text { mengambil keputusan }\end{array}$ & 2,43 & Buruk \\
\hline $\mathbf{1 9}$ & $\begin{array}{l}\text { Memberikan kebebasan } \\
\text { kepada bawahan untuk } \\
\text { bekerjasama dengan unit } \\
\text { lain }\end{array}$ & 2,62 & Sedang \\
\hline $\mathbf{2 0}$ & $\begin{array}{l}\text { Memberikan masukan } \\
\text { saat bawahan bertugas di } \\
\text { luar kantor }\end{array}$ & 3,62 & Baik \\
\hline & Rata - Rata & 3,68 & Baik \\
\hline
\end{tabular}

Dari hasil penelitian diatas, diperoleh angka 3,68 dengan kriteria penilaian baik. Menjelaskan bahwa Peran Kepala Polisi Sektor Wonoboyo Kabupaten Temanggung, sudah berjalan dengan baik.

Akan tetapi berdasarkan analisis perlu adanya peningkatan terutama dalam hal pemberian kepercayaan kepada bawahan untuk mengambil keputusan serta memberikan kebebasan kepada anggota untuk bekerjasama dengan unit lain.

Di kantor Polisi Sektor Wonoboyo Kabupaten Temanggung, hubungan yang terjalin antara pimpinan dan bawahan sudah berjalan dengan baik dan cukup optimal akan tetapi masih perlu adanya peningkatan agar dapat membantu masyarakat yang memerlukan bantuan terutama dalam bidang hukum.

\section{B. Analisis deskriptif data variabel (y) Faktor yang menentukan kinerja anggota.}

Dari hasil penelitian yang sudah penulis lakukan tentang "Pengaruh Gaya Kepemimpinan Kapolsek Terhadap Kinerja Anggotanya di Polsek Wonoboyo Kabupaten Temanggung" penulis akan menguraikan jawabanjawaban responden terhadap beberapa indikator pertanyaan mengenai Faktor yang menentukan kinerja anggota sebagai berikut :

Tabel 1.7

Rekapitulasi Jawaban Responden tentang kinerja anggota di kantor Polisi Sektor Wonoboyo Kabupaten Temanggung

\begin{tabular}{|c|l|c|c|}
\hline No & \multicolumn{1}{|c|}{ Indikator } & Skor & $\begin{array}{c}\text { Kriteria } \\
\text { Penilaian }\end{array}$ \\
\hline 1 & $\begin{array}{l}\text { Banyaknya hasil kerja } \\
\text { sesuai dengan waktu } \\
\text { kerja yang ada }\end{array}$ & 4,00 & Baik \\
\hline 2 & $\begin{array}{l}\text { Ketepatan, ketelitian, } \\
\text { kerapihan dan kualitas } \\
\text { hasil pekerjaan }\end{array}$ & 4,00 & Baik \\
\hline 3 & $\begin{array}{l}\text { Mengikuti instruksi, } \\
\text { inisiatif, rajin, serta } \\
\text { sikap hati-hati }\end{array}$ & 5,00 & Sangat Baik \\
\hline 4 & $\begin{array}{l}\text { Sikap terhadap anggota } \\
\text { lainnya dan pekerjaan }\end{array}$ & 5,00 & Sangat Baik \\
\hline \multicolumn{2}{|c|}{ Rata-rata } & 4,50 & Sangat Baik \\
\hline
\end{tabular}

Dari hasil penelitian di atas, di peroleh angka 4,50 dengan kriteria penilaian Sangat baik. Menjelaskan bahwa kinerja anggota kepolisian yang meliputi Kuantitas kerja, kualitas kerja, 
dapat tidaknya diandalkan, dan kerjasama di Kantor Polisi Sektor Wonboyo sudah berjalan dengan baik.

Akan tetapi berdasarkan analisis peneliti kinerja anggota kepolisian juga harus didukung oleh faktor sumber daya manusia yang memadai baik tingkat pendidikan maupun kemampuannya serta sarana dan pra sarana yang memadai.

Di kantor Polisi Sektor Wonoboyo Kabupaten Temanggung tingkat pendidikan pegawai masih minim. Dan minimnya pelatihan yang menunjang tugas anggota sesuai dengan tugas, pokok, dan fungsi (TUPOKSI) serta penyediaan fasilitas yang menunjang anggota dalam menjalankan tugasnya.

\subsubsection{Analisa Data}

A. Analisa Pengaruh Gaya Kepemimpinan Terhadap Kinerja anggota dengan menggunakan Rank Spearman

\section{B. Uji Hipotesis}

Hipotesis yang diajukan penulis dalam penelitian ini adalah:

HO : $\rho=0$ : Tidak terdapat pengaruh antara Gaya kepemimpinan dengan kinerja anggota.

H1 : $\rho=0$ : Terdapat pengaruh antar Gaya Kepemimpnan dengan kinerja anggota.

\section{Hasil Uji Hipotesis Menggunakan SPSS 16.00}

Tabel 1.8

Hasil Uji Signifikansi dengan
SPSS 16.00

Correlations

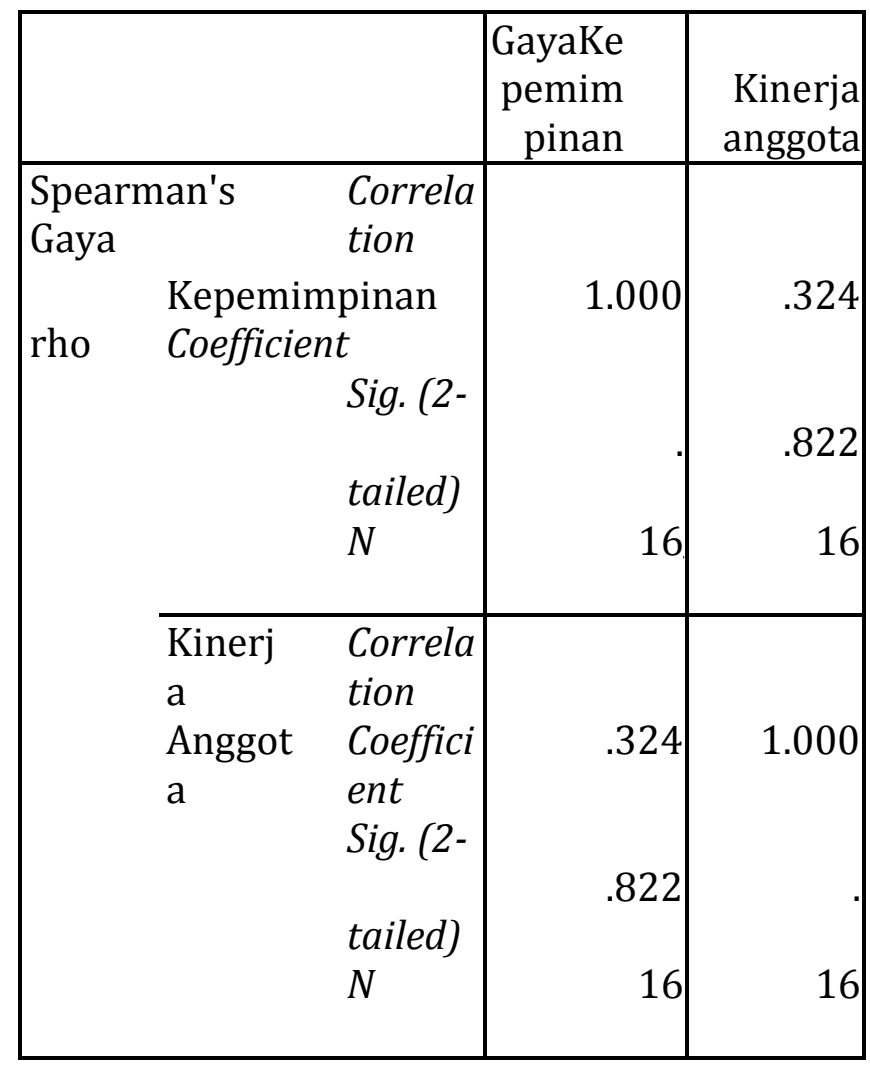

Berdasarkan tabel diatas dapat disimpulkan bahwa nilai korelasi antara variabel gaya kepemimpinan dengan variabel kinerja adalah sebesar 0,324 artinya semakin ideal gaya kepemimpinan kapolsek maka semakin optimal kinerja anggota besaran koefisien korelasi adalah dengan arah negatif.

Berdasarkan tabel interpretasi koefisien korelasi Sugiyono korelasi tersebut termasuk pada kategori 
hubungan yang kuat, dan level signifikansi menunjukkan nilai 0,822 yang jauh lebih besar dari 0,1 yang berarti signifikan, artinya dapat di generalisasikan ke seluruh populasi dimana sampel diambil.

Kemudian untuk mengetahui sejauh mana variabel Gaya Kepemimpinan (X) mempengaruhi variabel kinerja anggota (Y) dalam penelitian ini, maka digunakan perhitungan koefisien determinasi (Kd), yaitu:

$$
\begin{aligned}
& K d=\rho^{2} \times 100 \% \\
& K d=0,324^{2} \times 100 \% \\
& K d=0,104 \times 100 \% \\
& K d=10,4 \%
\end{aligned}
$$

Dari perhitungan tersebut dapat ditafsirkan bahwa Kinerja anggota di Kantor Polisi Sektor Wonoboyo lebih dipengaruhi oleh Gaya kepemimpinan $(10,4 \%)$, dan $(89,6 \%)$ oleh faktor lain, seperti motivasi, pengawasan, dan lainlain, tapi tidak diteliti.

\subsubsection{Gaya kepemimpinan yang diterapkan oleh Kapolsek Wonoboyo Kabupaten Temanggung}

Berdasarkan hasil dan analisa bahwa gaya kepemimpinan yang diterapkan oleh Kepala Polisi Sektor Wonoboyo di peroleh angka 3,68 dengan kriteria penilaian baik. Dengan berbagai macam jenis Gaya kepemimpinan dan penilain yaitu, gaya direktif dengan angka 3,62 dengan kriteria penilaian baik, gaya suportif dengan angka 3,79 dengan kriteria penilaian baik, gaya partisipatif dengan angka 3,45 dengan kriteria penilaian baik, gaya berorientasi prestasi dengan angka 3,65 dengan kriteria penilaian baik, dan gaya pendelegasian dengan angka 3,02 dengan kriteria penilaian sedang. Hal ini menjelaskan bahwa Peran Kepala Polisi Sektor Wonoboyo, sudah berjalan dengan baik. Akan tetapi berdasarkan analisis perlu adanya peningkatan terutama dalam hal pemberian kepercayaan kepada bawahan untuk mengambil keputusan serta memberikan kebebasan kepada anggota untuk bekerjasama dengan unit lain, serta saat menjalankan tugas diluar kantor.

\subsubsection{Apakah kinerja Anggota Polsek Wonoboyo Kabupaten Temanggung telah maksimal}

Berdasarkan hasil dan analisa bahwa di peroleh angka 4,50 dengan kriteria penilaian Sangat baik. Menjelaskan bahwa kinerja anggota kepolisian telah maksimal. Hal ini meliputi Kuantitas kerja, kualitas kerja, dapat tidaknya diandalkan, dan kerjasama yang dilakukan oleh paraanggota di Kantor Polisi Sektor Wonboyo sudah berjalan dengan baik. Akan tetapi berdasarkan analisis peneliti kinerja anggota kepolisian juga harus didukung oleh faktor sumber daya manusia yang memadai baik tingkat pendidikan maupun kemampuannya serta sarana dan prasarana yang memadai. Di kantor Polisi Sektor Wonoboyo tingkat pendidikan pegawai masih minim, dan beberapa fasilitas juga masih kurang memadai dalam menunjang pekerjaan anggota. 


\subsubsection{Pengaruh gaya kpemimpinan Kapolsek terhadap kinerja anggotanya di Polsek Wonoboyo Kabupaten Temanggung}

Berdasarkan hasil dan analisa bahwa gaya kepemimpinan yang diterapkan oleh Kepala Polisi Sektor Wonoboyo di peroleh angka 3,68 dengan kriteria penilaian baik. Hal ini dipengaruhi oleh Gaya kepemimpinan $(10,4 \%)$, dan $(89,6 \%)$ oleh faktor lain, seperti motivasi, pengawasan, dan lain-lain, tapi tidak diteliti, ini menjelaskan bahwa Peran Kepala Polisi Sektor Wonoboyo, sudah berjalan dengan baik. Akan tetapi berdasarkan analisis perlu adanya peningkatan terutama dalam hal penerapan Gaya kepemimpinan yang dianggap masih kurang, dan Kepala Polisi Sektor Wonoboyo harus lebih memberikan kepercayaan kepada bawahan untuk mengambil keputusan serta memberikan kebebasan kepada anggota untuk bekerjasama dengan unit lain, serta saat menjalankan tugas diluar kantor.

\subsection{IMPLIKASI}

\subsubsection{Implikasi Teoritis}

Implikasi teoritis yang dihasilkan adalah bahwa analisis dari pembahasan sudah sesuai dan relevan dengan teori yang digunakan dalam penelitian ini sehingga, diperoleh angka 3,68 dengan kriteria penilaian baik dipengaruhi oleh Gaya kepemimpinan sebesar (10,4\%), dari hasil ini dapat dilihat bahwa Gaya Kepemimpinan merupakan salah satu faktor pendukung yang ada di Polsek Wonoboyo.

\subsubsection{Implikasi Praktis}

Implikasi praktis dari penelitian ini dianggap cukup baik meskipun jika dilihat dari segi kepemimpinan yang hanya menghasilkan angka penilaian sebesar 10,4 \% namun secara keseluruhan hubungan korelasi antara pimpinan dan bawahan cukup kuat nilai korelasi antara variabel gaya kepemimpinan dengan variabel kinerja adalah sebesar 0,324 artinya semakin ideal gaya kepemimpinan kapolsek maka semakin optimal kinerja anggotanya. besaran koefisien korelasi adalah dengan arah negatif, korelasi tersebut termasuk pada kategori hubungan yang kuat, dan level signifikansi menunjukkan nilai 0,822 yang jauh lebih besar dari 0,1 yang berarti signifikan, artinya dapat digeneralisasikan keseluruh populasi dimana sampel diambil.

\section{KESIMPULAN}

Adapun kesimpulan yang dapat penulis sampaikan adalah sebagai berikut :

1. Setelah dilakukan analisis terhadap setiap indikator dari variabel Gaya Kepemimpinan yang diterapkan di Kantor Polisi Sektor Wonoboyo Kabupaten Temanggung bahwa skor rata-rata untuk semua indikator adalah sebesar 3.68 dan menurut kriteria penilaiaan berada pada kategori Baik.

2. Selain Gaya kepemimpinan, variabel kinerja anggota Polisi Sektor Wonoboyo Kabupaten Temanggung di peroleh skor rata-rata sebesar 4,50 yang menurut 
kriteria penilaian berada pada kategori

Sangat Baik. Hal ini dapat diartikan bahwa kinerja anggota di kantor Polisi Sektor Wonoboyo sangat memuaskan.

3. Faktor Gaya kepemimpinan yang diterapkan oleh Kepala Polisi Sektor Wonoboyo cukup berpengaruh hal ini dapat dilihat dari skor yang diperoleh yaitu sebesar 3,68 dengan kriteria penilaian baik atau dengan persentase sebesar $(10,4 \%)$, sementara faktor lain memperoleh persentase sebesar $(89,6 \%)$ yang meliputi beberapa faktor diantaranya ialah, motivasi, pengawasan, dan lain-lain. Hal ini menjelaskan bahwa Peran Kapolsek sudah berjalan baik.

\section{DAFTAR PUSTAKA}

\section{A. BUKU}

Anoraga, Pandji. 2003. Psikologi

Kepemimpinan. Jakarta: Rineka Cipta

Hersey, 2004. Kunci Sukses Pemimpin

Situasional. Jakarta Delaprasata Jersey Sudjana, N. dan Ibrahim, 2004,

Penelitian dan Penilaian

Pendidikan. Bandung: Sinar Baru Algensindo.

Kartini Kartono. 2011. Pemimpin dan Kepemimpinan, Jakarta: PT. Rajawali grafindo Persada.

Martoyo, 2003. Kepemimpinan

Mengefektifkan Organisasi.

Yogyakarta: Gajah Mada University

Press. 